\title{
Comparison of the prevalence rates of HIV infection between men who have sex with men (MSM) and men in the general population in sub-Saharan Africa: a systematic review and meta-analysis
}

P. H. Septime Hessou ${ }^{1,2,3^{*}}$, Yolaine Glele-Ahanhanzo ${ }^{4}$, Rheda Adekpedjou ${ }^{5}$, Carin Ahouada ${ }^{2}$, R. Christian Johnson ${ }^{3}$, Michel Boko ${ }^{3}$, Hervé Tchala Vignon Zomahoun ${ }^{5}$ and Michel Alary ${ }^{2}$

\begin{abstract}
Background: According to the 2015 report of the Joint United Nations Program on Human Immunodeficiency Virus (HIV) and Acquired Immune Deficiency Syndrome (AIDS), the prevalence rates of HIV infection among men who have sex with men (MSM) varied from 6 to 37\% depending on the country, far exceeding the national prevalence rates. The present study on HIV infection among men who have sex with men in sub-Saharan Africa was conducted to describe the different sampling methods used to identify this target population and compare the prevalence rates of HIV infection among MSM to that of men in the general population.

Methods: The selection of studies to be included was carried out in the principal electronic databases. The 2009 Preferred Reporting Items for Systematic Reviews and Meta-Analyses (PRISMA) directives were used throughout the entire process. Bias evaluation was performed using the Mixed Methods Appraisal Tool. For each country, HIV prevalence values in both groups were calculated. A prevalence ratio was also calculated to compare the prevalence rates of the two groups.

Results: Seventeen articles were selected. Most of the studies (82.35\%) used the Respondent-Driven Sampling method. The average prevalence rate was 17.81\% (range: 3.7-33.46) for MSM and 6.15\% (range: 0.5-19.7) for men in the general population. Overall, the human HIV prevalence rate was 4.94 times higher among MSM than among men in the general population $(95 \% \mathrm{Cl}: 2.91-8.37)$. The western and central regions of Africa, as well as lowprevalence countries (prevalence < 1\%), had very high prevalence ratios: 14.47 (95\% Cl: 9.90-21.13) and 28.49 (95\% Cl: 11.47-72.71), respectively.
\end{abstract}

Conclusion: MSM are at higher risk of HIV infection than men in the general population. The prevalence ratios are particularly elevated in West and Central Africa as well as in low-prevalence countries. Close monitoring of the situation, research and preventive measures are essential to control the epidemic amongst MSM.

Keywords: HIV, Men who have sex with men (MSM), Prevalence, Sub-Saharan Africa

\footnotetext{
* Correspondence: shessou@yahoo.fr

${ }^{1}$ Centre National de Référence de Recherche et de Prise en Charge du Sida

(CNRRPEC-CNHU/Bénin), Cotonou, Benin

${ }^{2}$ Institut Régional de Santé Publique (IRSP), Université d'Abomey-Calavi

(UAC), Ouidah, Bénin

Full list of author information is available at the end of the article
}

(c) The Author(s). 2019 Open Access This article is distributed under the terms of the Creative Commons Attribution 4.0 International License (http://creativecommons.org/licenses/by/4.0/), which permits unrestricted use, distribution, and reproduction in any medium, provided you give appropriate credit to the original author(s) and the source, provide a link to the Creative Commons license, and indicate if changes were made. The Creative Commons Public Domain Dedication waiver (http://creativecommons.org/publicdomain/zero/1.0/) applies to the data made available in this article, unless otherwise stated. 


\section{Background}

Unprotected sex between men facilitates the transmission of sexually transmitted infections (STIs) and human immunodeficiency virus (HIV) [1]. Unprotected anal penetration is high-risk behaviour for HIV transmission. In the 2015 UNAIDS (Joint United Nations Program on HIV/AIDS) report, studies in sub-Saharan Africa found prevalence rates of HIV infection ranging from 6 to 37\% among MSM. As the observed prevalence rate of HIV in the general population was between 0.1 and $19 \%$, the prevalence rate among men who have sex with men (MSM) was often 13 to 17 times higher [2].

In 2015, according to the progress reports on the global AIDS (Acquired Immune Deficiency Syndrome) response, the highest prevalence rates of HIV infection among MSM were as follows: $19 \%$ in central and western Africa; $15 \%$ in southern and eastern Africa; $12 \%$ in Latin America; $11 \%$ in the Asia-Pacific region; and 8\% in central and western Europe and North America [2-4]. Although data existed on the prevalence of HIV infection among MSM in countries in sub-Saharan Africa, very few systematic reviews have been conducted to allow for a comprehensive summary of the prevalence data, to measure the extent of this disease among MSM and to compare it to that of the general population [3, 5]. The only systematic review of this type that we identified was published 12 years ago and was not specific to sub-Saharan Africa [6]. Moreover, although much more attention has been given to African MSM since the publication of this review, access to MSM in many countries in sub-Saharan Africa remains generally difficult, particularly in terms of their potential participation in epidemiological studies. This is due to discrimination and/ or criminalization of their sexual orientation, as well as the social stigma associated with their behaviour. Few or no literature reviews have identified the different methods used to sample this population in epidemiological studies in sub-Saharan Africa [1]. A comparison in sub-Saharan Africa will help MSM emerge from the shadows. It will highlight their heavy burden in terms of new HIV infections and draw the attention of public authorities to the need to take this target into account in intervention programs in a hostile environment. Thus, the purpose of our systematic review is twofold: to compare the prevalence of HIV infection among MSM and men in the general population, and to describe the various sampling methods used to reach this "hidden" MSM population in sub-Saharan Africa.

\section{Methods}

This systematic review was conducted in accordance with the Preferred Reporting Items for Systematic Reviews and Meta-Analyses (PRISMA) statement [7].

\section{Inclusion criteria}

The inclusion criteria for the studies were as follows: (1) the study population comprised MSM populations in subSaharan Africa aged 18 years and over; (2) exposure was defined as having voluntary and consensual sexual intercourse with a man at least once in the 12 months prior to the study; (3) the outcome sought was an HIV infection rate whose frequency measurement was expressed as prevalence and was based on actual HIV tests conducted in the course of the study; (4) they took place in a country where Demographic Health Surveys (DHS) provided information on the prevalence of HIV infection for men from the general population within a few years of the MSM study; and (5) the study design was cross-sectional or had a cross-sectional component of recruitment in a longitudinal study. General population HIV prevalence estimates for a given country were all based on contemporary DHS surveys in the same country. The latter included all men, and therefore could include some MSM. There were no period restrictions or year limitations. All studies with a sample size of less than 50 subjects and/or self-reported HIV infection were excluded. We found that studies with sample sizes of less than 50 subjects were not sufficiently precise to be included and we excluded those with selfreported HIV status to avoid information bias, be more specific and facilitate comparisons.

\section{Data source and search strategy}

The search was carried out using the following electronic databases: PubMed, EMBASE, Cochrane, Web of Science, Scopus and Google Scholar. The PICOS (Population Intervention Comparison Outcomes Study design) approach was used in this search strategy (Additional file 1). The following keywords were employed in this search: "HIV," "prevalence," "men," "men who have sex with men," and "sub-Saharan Africa." The published studies included did not deal with both the MSM and general male population simultaneously (Additionnel file 2). They provided the HIV infection prevalence among MSM. In an approach similar to that of Baral et al. [6], we consulted the Macro International database for Demographic and Health Surveys in each country in sub-Saharan Africa (http://dhsprogram.com). This led to estimates of the prevalence of HIV infection among men in the general population. For each study included, the DHS from its corresponding country was selected: this DHS was contemporary to the study on the prevalence of HIV among MSM (most often the same year or within one to 3 years of the selected MSM study). Otherwise, the grey literature was consulted, mainly UNAIDS and WHO periodic reports, but also monitoring reports of HIV interventions at country level, periodic progress reports on the fight against HIV in different countries, and reports on the national census of 
populations at a countrywide level to complete the information necessary to meet the objectives of this systematic review.

\section{Selection of articles}

Two independent reviewers selected the articles based on the inclusion criteria; this was carried out in two stages. The first selection was made from the titles and abstracts of the articles. For a mutual and reproducible understanding between the two reviewers, a pilot test was carried out on approximately fifteen samples before the first selection (5\% of the 299 articles randomly drawn after the elimination of duplicates). The inter-reviewer agreement represented by the Kappa coefficient was $74 \%$. At the end of the first selection, 104 articles were selected out of the 299 initially pre-selected: the Kappa coefficient for the two reviewers was $92 \%$. The second selection was carried out by reading the full text of the pre-selected 104 articles. The only articles selected were those that fully and completely met the inclusion criteria. This second selection was also preceded by a pilot test: it was carried out on 5 articles (5\% of 104). The Kappa coefficient obtained was $85 \%$. A summary of the key points was made to validate the final selection of articles by the two reviewers. The actual selection made it possible to definitively retain 17 articles; the interreviewer agreement was $71 \%$. At each stage of the selection process, disagreements were resolved through discussion and consensus between the two reviewers (Fig. 1).

\section{Data collection}

Data collection was carried out using a previously designed tool (Additional file 3). It was used to collect the following information: the identification of studies, target population, method used, software employed for data

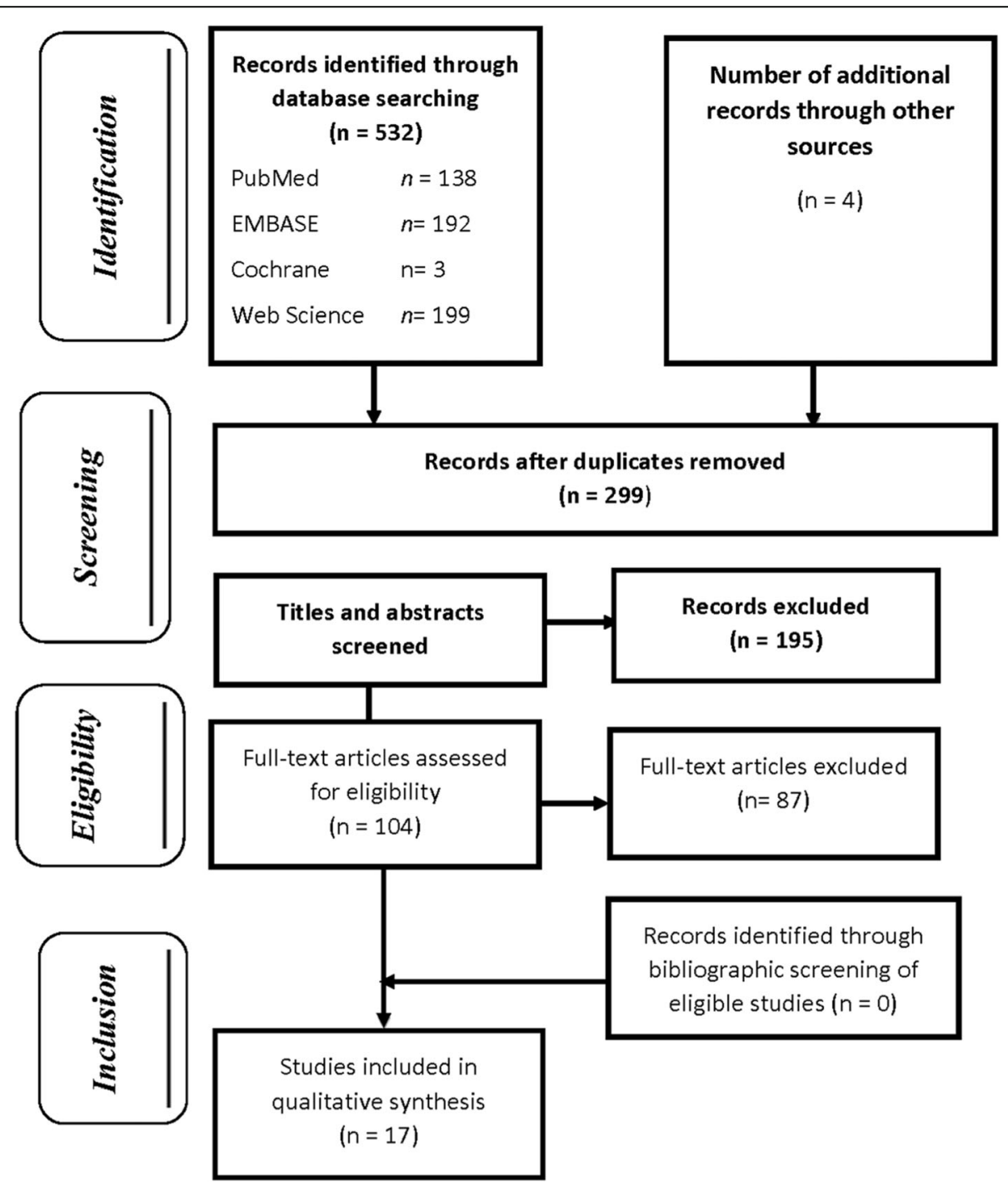

Fig. 1 Flow chart of articles selection for the systematic review (PRISMA) 
analysis, and results. This extraction was carried out independently by two (2) reviewers. Disagreements between the two were usually resolved through discussion based on the information to be retrieved as found in the data collection guide. The assessment of the risks of bias was performed using the Mixed Methods Appraisal Tool (MMAT) [8].

\section{Statistical analysis}

For each MSM study included, we used HIV prevalence as reported for this population. HIV prevalence estimates in the general male population were taken from the results of contemporary DHS surveys in the same country (Table 1). To estimate the uncertainty associated with these measurements, estimates of the prevalence of HIV among MSM and men in the general population were used for each country with $95 \%$ confidence intervals $(95 \% \mathrm{CI})$. The prevalence ratio (PR) was calculated by dividing HIV prevalence among MSM by that of men in the general population. Using meta-analysis, the pooled PR estimates of all the countries included were made using random-effect models. The heterogeneity between studies was assessed by examining the forest plot and Higgins $\mathrm{I}^{2}$ statistic. An $\mathrm{I}^{2}$ greater than $50 \%$ suggests high heterogeneity. Subgroup analysis was performed using PR estimates pooled according to the different geographic regions of sub-Saharan Africa (western, central, eastern and southern). Another subgroup analysis was performed according to the UNAIDS classification of the HIV epidemic level in the countries (mixed epidemic $=$ prevalence $<1 \%$; generalized epidemic $=$ preva lence $1-5 \%$; hyper-endemic $=$ prevalence $>5 \%)[2,42-44]$. It is likely that MSM was included in some samples of men of childbearing age in the general population. Sensitivity analysis was performed to assess the impact of misclassification of exposure. This sensitivity analysis was carried out according to the approach used by Baral and al [6].. For each country, the total population of MSM (estimated from the sample) was subtracted from the general population of men of childbearing age. The prevalence of HIV infection among MSM was recalculated for a hypothetical population where MSM did not contribute to the prevalence of HIV in the general population. Descriptive analysis and meta-analysis were performed using the statistical software SAS version 9.1 and Revman 5.

\section{Results}

The study selection process began on November 15, 2016. Five hundred thirty-six documents were found: 532 studies in electronic databases and 4 in UNAIDS reports. After eliminating the duplicates, 299 documents were retained. After reading their titles and abstracts and checking whether they met inclusion criteria, some studies were excluded (195). Thus, 104 articles were selected to be read in full. The reasons for exclusion were related to non-compliance with the target population, geographic area, exposure, type of estimate and frequency measurements calculated in the study. At the end of this process, 17 articles completely met the inclusion criteria and were selected (Fig. 1).

The characteristics of the studies included in this literature review are summarized in Table 1 . The average prevalence rate of HIV was $17.81 \%$ among MSM (minimum, $3.7 \%$; maximum $33.46 \%$ ) and $6.15 \%$ among men in the general population (minimum, $0.5 \%$; maximum, $19.7 \%$ ).

All the studies were carried out in the capitals and/or major cities of the countries included. The Respondent-Driven Sampling (RDS) method was used by most of the studies (82.35\%) to reach "hidden" populations such as MSM.

Regardless of the prevalence rate of HIV infection in the general population, type of epidemic and regional classification, the prevalence ratio of HIV infection among MSM compared with men in the general population varied from 0.89 (95\% CI: $0.69-1.16)$ to 43 (95\% CI: 25.56-72.34). Overall, the prevalence rate of HIV infection was 4.94 times higher among MSM than among men in the general population (95\% CI: 2.91-8.37). Additionally, there was heterogeneity between studies: $\mathrm{I}^{2}=98 \%, p<0.00001$ (Table 2).

Subgroup analyses indicated that in western and central Africa, the prevalence of HIV infection was 14.47 times higher in MSM than in men in the general population (95\% CI: 9.90-21.13, $p<0,0000)[10,14,16,18,20$, $26,37,45]$. In eastern Africa, the prevalence of HIV infection was 3.39 times higher in MSM than in men in the general population (95\% CI: $2.27-5.08 ; p<0,00001$ ). In southern Africa, the prevalence of HIV infection was 1.24 times higher among MSM than among men in the general population (95\% CI: $0.91-1.69 ; p=0.17$ ) (Table 3).

The prevalence of HIV infection in low-prevalence countries (prevalence $<1 \%$ ) was 28.49 times higher among MSM than among men in the general population (95\% CI: 11.47-72.71, $p=0.03)$. In medium-prevalence countries (prevalence 1-5\%), the prevalence of HIV infection was 8.62 times higher among MSM than among men in the general population (95\% CI: 5.01-14.83, $\mathrm{p}<0,00001)$. In countries with a high prevalence (prevalence $>5 \%$ ), the prevalence of HIV infection was 1.66 times higher among MSM than among men in the general population $(95 \% \mathrm{CI}$ : $1.07-2.52, p<0$, 00001) (Fig. 2).

Sensitivity analysis suggested that the prevalence of HIV infection was 4.54 times higher among MSM than among men in the general population, excluding MSM (95\% CI: 2.66-7.75, p < 0, 00001) (Fig. 3).

\section{Discussion}

To study the HIV epidemic among MSM and the link between this epidemic and its spread in the general 


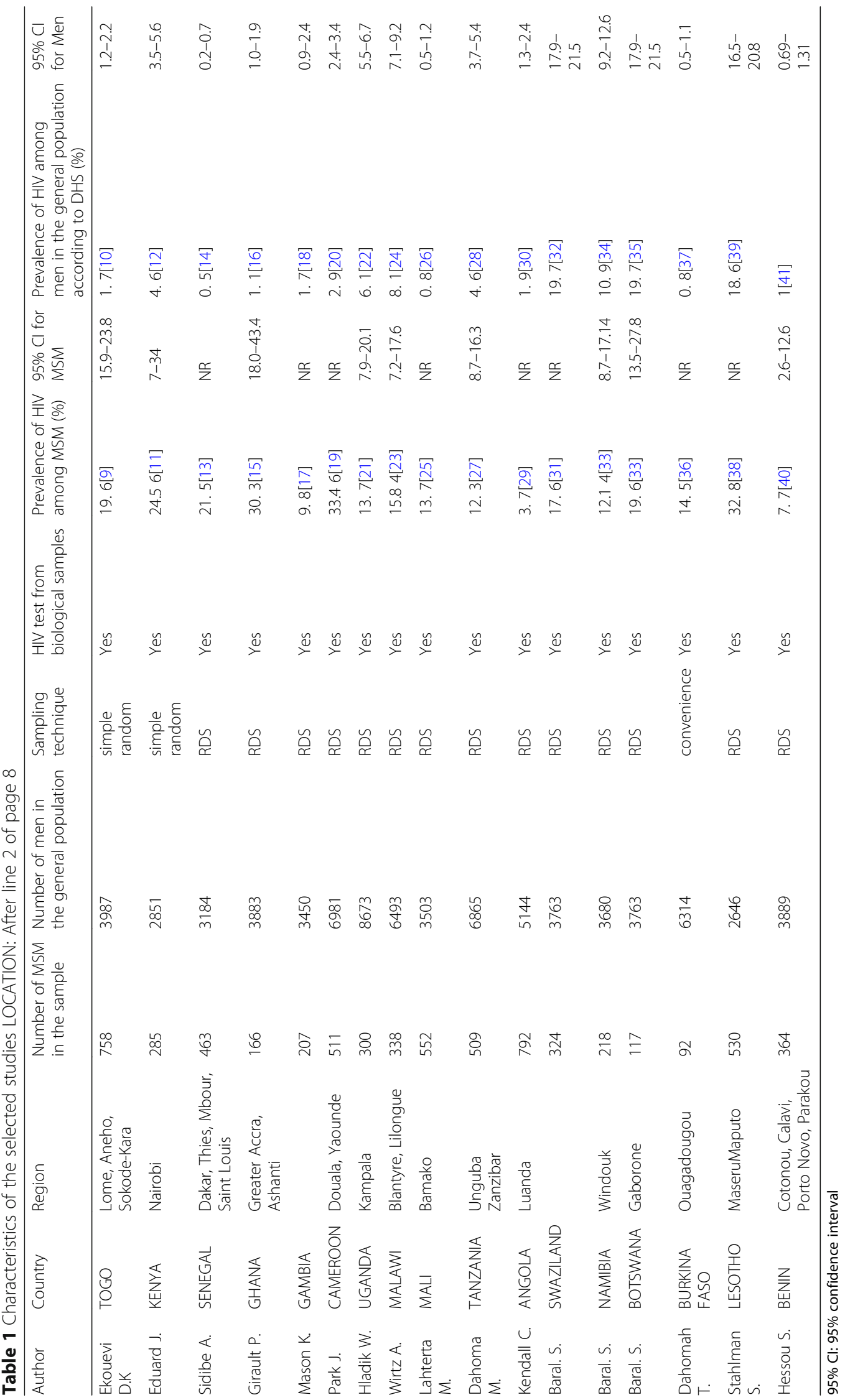


Table 2 Prevalence ratio of HIV infection among MSM compared to men in the general population of countries in Sub-Saharan Africa

\begin{tabular}{lllll}
\hline Country & $\mathrm{N}$ & Epidemic level & Prevalence Ratio* & $95 \% \mathrm{Cl}$ \\
\hline Senegal & 3184 & Generalized & 43.00 & {$[25.56-72.34]$} \\
Ghana & 3883 & Generalized & 27.15 & {$[18.68-40.62]$} \\
Burkina Faso & 6314 & Generalized & 18.13 & {$[8.97-36.14]$} \\
Mali & 3503 & Generalized & 17.13 & {$[11.21-26.17]$} \\
Cameroon & 6981 & Mixed & 11.54 & {$[9.61-13.85]$} \\
Togo & 3987 & Generalized & 11.50 & {$[8.46-15.62]$} \\
Benin & 3889 & Mixed & 7.70 & {$[4.80-12.36]$} \\
Gambia & 3450 & Generalized & 5.76 & {$[3.54-9.38]$} \\
Kenya & 2851 & Mixed & 5.34 & {$[4.10-6.95]$} \\
Angola & 5144 & Generalized & 4.04 & {$[2.67-6.10]$} \\
Tanzania & 6865 & Generalized & 2.67 & {$[2.08-3.44]$} \\
Uganda & 8673 & Generalized & 2.25 & {$[1.65-3.05]$} \\
Lesotho & 2646 & Hyper-endemic & 1.76 & {$[1.52-2.04]$} \\
Malawi & 6493 & Mixed & 1.53 & {$[1.14-2.06]$} \\
Namibia & 3650 & Hyper-endemic & 1.14 & {$[0.77-1.64]$} \\
Botswana & 3763 & Hyper-endemic & 1.00 & {$[0.69-1.45]$} \\
Swaziland & 3763 & Hyper-endemic & 0.89 & {$[0.69-1.16]$} \\
Total & 79,069 & & $4.94^{* *}$ & {$[2.91-8.37]$} \\
\hline N sample size & of $m$ by county & &
\end{tabular}

$n=$ sample size of men by country

* Prevalence ratio of HIV infection among MSM compared with that among men in the general population

** $p<0.00001, I^{2}=98 \%$

$95 \% \mathrm{Cl}: 95 \%$ confidence interval

population, we conducted a systematic review of studies on HIV among MSM in sub-Saharan African countries. Overall, most of the studies used RDS as a sampling technique to reach MSM. In total, the prevalence of HIV was five times higher among MSM than among men in the general population. The western and central regions of Africa, as well as low-prevalence countries (prevalence $<1 \%$ ), had very high PR.

The data suggest that RDS is the most commonly used method for sampling MSM. To provide reliable estimates from a population that is difficult to access, this scientific method is also used to recruit MSM. This respondent-led sampling strategy is a probabilistic sampling method specifically designed to obtain samples from so-called "hidden" and socially organized populations. It is characterized by the sample to be studied being created by the MSM themselves through chain referrals [29, 46-48]. This is a variant of "snowball sampling;" however, unlike the latter, it has been shown that RDS produces unbiased estimates under certain conditions [49-53].

Regarding the regional analysis, the western and central regions of Africa had a very high PR because the national prevalence of HIV infection among men in the general population was quite low compared with that among MSM. According to the UNAIDS criteria, this situation makes MSM priority targets in these regions $[2,54]$. The PRs are high in countries with mixed and generalized epidemics, while they are close to one in some of the massive hyper-endemic countries. Because the national prevalence in these countries was already very high, the prevalence of HIV among men in the general population was very close to that of MSM. In this context, the national response to HIV infection at the country level could also have a direct influence on the MSM subpopulation [2, 54]. We also noted that the PR was increased when the prevalence of HIV among men in the general population was decreased. This finding could be explained by the observation that, when the national prevalence is low, the prevalence in the MSM group is higher. Thus, MSM will constitute a highrisk group and will be a priority target of response measures. This systematic review draws its strength from the precision of the combined estimates of PR and a large aggregate size of samples of MSM and men in the general population. However, it is not without its limitations.

\section{Limitations}

In general, access to MSM in many African countries has been difficult, particularly in terms of participation in studies because of discrimination and/or criminalization of their sexual orientation. The problems of participants'safety and security in certain contexts would result in low levels of self-identification among MSM $[6,15,55]$. These barriers have likely limited the number and quality of studies and the availability of data on MSM in many countries in sub-Saharan Africa. Normally, the correct and efficient use of the RDS technique as a sampling method would help to partially solve this problem. Nevertheless, the literature also shows that RDS can give biased estimates when the recruitment does not completely follow the RDS principles in practice. This could be another limitation of our analysis [49-53].

Table 3 Prevalence ratio of HIV infection among MSM compared with that among men in the general population in countries in sub-Saharan Africa by region, prevalence level and type of epidemic

\begin{tabular}{lllll}
\hline Parameters & Different levels & Number of countries & $\mathrm{PR}$ [95\% Cl M-H random] & $p$ value \\
\hline Western and Central & 8 & $14.47[9.90-21.13]$ & $<.00001$ \\
& Eastern & 4 & $3.39[2.27-5.08]$ & $<0.00001$ \\
Southern & 5 & $1.24[0.91-1.69]$ & 0.17 \\
\hline
\end{tabular}




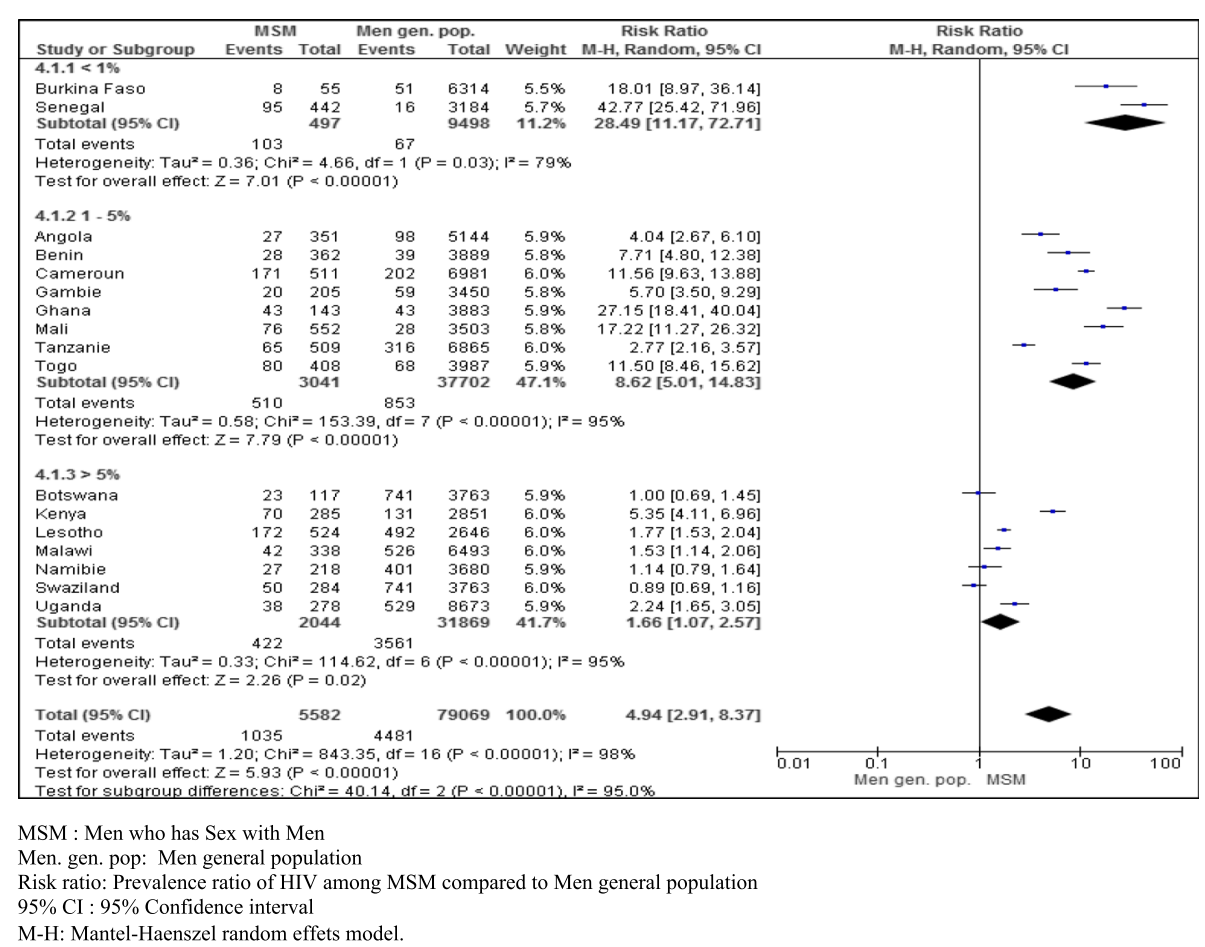

Fig. 2 Prevalence ratio of HIV infection among MSM compared to men in the general population according to the prevalence levels of countries in sub Saharan Africa

Some of the studies included in this analysis used convenience sampling or a cross-sectional design and, therefore, may not be representative of MSM. To determine the risk of HIV infection among MSM in countries in subSaharan Africa, we used the DHS estimates of the prevalence in the general male population for each country as the unexposed population to calculate PR. However, this approach does not make the populations comparable and may have affected the validity of our results. MSM tend to congregate in urban areas, explaining, at least in part, why most of the reported studies were urban. This may limit the generalizability of the studies. Although $82.35 \%$ of the

\begin{tabular}{|c|c|c|c|c|c|c|c|c|c|c|}
\hline \multirow[b]{2}{*}{ Study or Subgroup } & \multicolumn{2}{|c|}{ MSM } & \multicolumn{2}{|c|}{ Men gen. pop. } & \multirow[b]{2}{*}{ Weight } & \multirow{2}{*}{$\begin{array}{c}\text { Risk Ratio } \\
\text { M-H, Random, } 95 \% \mathrm{Cl}\end{array}$} & \multirow{2}{*}{\multicolumn{4}{|c|}{$\begin{array}{c}\text { Risk Ratio } \\
\text { M-H, Random, } 95 \% \mathrm{Cl}\end{array}$}} \\
\hline & Events & Total & Events & Total & & & & & & \\
\hline Angola & 27 & 351 & 98 & 5144 & $5.9 \%$ & $4.04[2.67,6.10]$ & & & $\rightarrow$ & \\
\hline Benin & 28 & 362 & 39 & 3889 & $5.8 \%$ & $7.71[4.80,12.38]$ & & & & - \\
\hline Botswana & 23 & 117 & 741 & 3763 & $5.9 \%$ & $1.00[0.69,1.45]$ & & & - & \\
\hline Burkina Faso & 8 & 55 & 51 & 6314 & $5.5 \%$ & $18.01[8.97,36.14]$ & & & & . \\
\hline Cameroun & 171 & 511 & 202 & 6981 & $6.0 \%$ & $11.56[9.63,13.88]$ & & & & - \\
\hline Gambie & 20 & 205 & 59 & 3450 & $5.8 \%$ & $5.70[3.50,9.29]$ & & & & \\
\hline Ghana & 43 & 143 & 43 & 3883 & $5.9 \%$ & $27.15[18.41,40.04]$ & & & & $\rightarrow$ \\
\hline Kenya & 70 & 285 & 131 & 2851 & $6.0 \%$ & $5.35[4.11,6.96]$ & & & & \\
\hline Lesotho & 172 & 524 & 492 & 2646 & $6.0 \%$ & $1.77[1.53,2.04]$ & & & - & \\
\hline Malawi & 42 & 338 & 526 & 6493 & $6.0 \%$ & $1.53[1.14,2.06]$ & & & $\rightarrow$ & \\
\hline Mali & 76 & 552 & 28 & 3503 & $5.8 \%$ & $17.22[11.27,26.32]$ & & & & $\rightarrow$ \\
\hline Namibie & 27 & 218 & 401 & 3680 & $5.9 \%$ & $1.14[0.79,1.64]$ & & & - & \\
\hline Senegal & 95 & 442 & 16 & 3184 & $5.7 \%$ & $42.77[25.42,71.96]$ & & & & $\cdots$ \\
\hline Swaziland & 50 & 284 & 741 & 3763 & $6.0 \%$ & $0.89[0.69,1.16]$ & & & & \\
\hline Tanzanie & 65 & 509 & 316 & 6865 & $6.0 \%$ & $2.77[2.16,3.57]$ & & & $\rightarrow$ & \\
\hline Togo & 80 & 408 & 68 & 3987 & $5.9 \%$ & $11.50[8.46,15.62]$ & & & & $\rightarrow$ \\
\hline Uganda & 38 & 278 & 529 & 8673 & $5.9 \%$ & $2.24[1.65,3.05]$ & & & $\rightarrow$ & \\
\hline Total $(95 \% \mathrm{Cl})$ & & 5582 & & 79069 & $100.0 \%$ & $4.94[2.91,8.37]$ & & & & \\
\hline Total events & 1035 & & 4481 & & & & & & & \\
\hline $\begin{array}{l}\text { Heterogeneity: } \mathrm{Tau}^{2}= \\
\text { Test for overall effect. }\end{array}$ & $\begin{array}{l}1.20 ; \mathrm{Chi} \\
Z=5.93\end{array}$ & $\begin{array}{l}=843 \\
P<0.0\end{array}$ & $\begin{array}{l}.35, \mathrm{df}=1 \\
0001)\end{array}$ & $6(P<1$ & $00001) ; i^{2}$ & $=98 \%$ & $\begin{array}{cc}0.01 & 0.1 \\
\text { Favours [Men }\end{array}$ & gen pop. ${ }^{1}$ & Favours [t & $\begin{array}{l}10 \\
\text { SMI }\end{array}$ \\
\hline
\end{tabular}

MSM : Men who has Sex with Men

Risk ratio: Prevalence ratio of HIV among MSM compared to Men general population $95 \% \mathrm{CI}: 95 \%$ Confidence interval

M-H: Mantel-Haenszel random effets model.

Fig. 3 Assessment of the prevalence ratio of HIV infection among MSM compared to men in the general population and the prevalence of HIV infection among MSM compared to men in the general population of countries in sub Saharan Africa 
authors used the RDS method for sampling subjects, only half of them produced weighted data that considered the overall contribution of each referral chain $[44,56,57]$. This situation may affect the representativeness of the MSM in the studies. Otherwise, MSM are included in men of the general population. This could have increased estimates of HIV infection prevalence in the general population of men.

Selection bias is also possible because our research did not extend to unpublished articles and conference abstracts, which could affect the results of our systematic review. This could be partly responsible for the degree of associations observed in our study. To minimize this bias, DHS data and annual progress reports were sought to complement and refine the information provided by conventional databases.

The extent to which MSM are included, excluded or unidentified in these national estimates affects both their validity and the ability of our study to compare the prevalence of HIV among MSM with that among men in the general population. This may result in a classification bias or even an underestimation of the final result. However, the sensitivity analysis carried out for this purpose showed similar results in both groups.

\section{Conclusion}

The results of the present study reveal the following: HIV prevalence is significantly higher in the populations of men who have sex with men than in men in the general population and, more specifically, in men in sub-Saharan Africa. This phenomenon was observed independently of the type of epidemic, geographical location and epidemic level. These MSM populations are known to be difficult to access because they live in autarky, hidden because of the extent of stigma and discrimination against them, especially in African countries, and this required a technique of sampling and recruitment adapted to reach the largest number of these MSM. This situation calls for new measures to address an effective and efficient response to HIV infection in this key population for universal access to prevention, treatment, care and support according to the WHO's new 2015, 2016, 2017 guidelines for comprehensive and inclusive care of key populations. In addition, such populations in general, and particularly MSM, need to be integrated into epidemiological monitoring systems at the country level in sub-Saharan Africa. These innovations and actions can only provide substantive results if they are delivered in a socio-cultural and health environment of respect for gender identity and human rights. This way it will be possible to hope for a continuous and constant reversal of the trend of the HIV epidemic and achievement of the three 90x90x90 UNAIDS targets for sub-Saharan Africa.

\section{Supplementary information}

Supplementary information accompanies this paper at https://doi.org/10. 1186/s12889-019-8000-x.

Additional file 1: Table S1. Operationalization of the criteria for article selection by reviewers.

Additional file 2: Table S2. Detailed literature search strategies.

Additional file 3. Data collection guide.

\section{Abbreviations}

AIDS: Acquired Immune Deficiency Syndrome; DHS: Demographic and Health Surveys; HIV: Human Immunodeficiency Virus; MMAT: Mixed Methods Appraisal Tool; MSM: Men Who Have Sex With Men; PR: Prevalence Ratio; PRISMA: Preferred Reporting Items for Systematic Reviews and MetaAnalyses; RDS: Respondent-Driven Sampling Method; UNAIDS: The Joint United Nations Program on HIV and AIDS; WHO: World Health Organization

\section{Acknowledgements}

The authors are sincerely grateful to Frédéric Bergeron, information specialist for his advice and guidance in the documentary research strategy at the University of Laval in Quebec, Canada.

\section{Authors' contributions}

HPHS conceived the idea. All authors contributed to the search strategy. $\mathrm{HPSH}, \mathrm{AR}$ and YGA conducted the literature search, quality assessment, data extraction, first analysis. HPSH and YGA wrote the first draft manuscript. All authors contributed to the interpretation of the results and reviewed the manuscript. The final version has been read and approved by all the authors.

\section{Funding}

Not reported.

\section{Availability of data and materials}

The dataset used and analyzed during the current study are available from the first author on reasonable request.

Ethics approval and consent to participate

"Not applicable".

Consent for publication

"Not applicable".

\section{Competing interests}

The authors declare that they have no competing interests.

\section{Author details}

${ }^{1}$ Centre National de Référence de Recherche et de Prise en Charge du Sida (CNRRPEC-CNHU/Bénin), Cotonou, Benin. ${ }^{2}$ Institut Régional de Santé Publique (IRSP), Université d'Abomey-Calavi (UAC), Ouidah, Bénin. ${ }^{3}$ Centre de Recherche sur les Soins et Services de Première Ligne de I'Université Laval (CERSSPL-UL), Université Laval, Québec, Canada. ${ }^{4}$ Axe Santé des populations et pratiques optimales en santé Centre de Recherche du CHU de Québec, Université Laval, Hôpital du Saint-Sacrement, Quebec City, Canada. ${ }^{5}$ Centre Inter-facultaire de Formation et de Recherche en Environnement pour le Développement (CIFRED), Université d'Abomey-Calavi (UAC), Calavi, Benin.

Received: 12 October 2018 Accepted: 25 November 2019

Published online: 04 December 2019

\section{References}

1. Programme commun des Nations Unies sur le VIH/sida (ONUSIDA). Le VIH et les hommes qui ont des rapports sexuels avec les hommes au moyen orient et en Afrique du nord : d'une démarche de sensibilisation à une démarche d'engagement. Caire: ONUSIDA; 2012.

2. Programme commun des Nations Unies sur le VIH/sida (ONUSIDA). Rapport d'avancement sur le plan mondial 2014: visant à éliminer les nouvelles infections à VIH chez les enfants à l'horizon 2015 et maintenir leurs mères en vie. Genève: ONUSIDA; 2014. 
3. Paleologou V, Kontodimopoulos N, Stamouli A, Aletras V, Niakas D. Developing and testing an instrument for identifying performance incentives in the Greek health care sector. BMC Health Serv Res. 2006;6:118.

4. Programme commun des Nations Unies sur le VIH/sida (ONUSIDA). Le sida en chiffres 2015. Genève: ONUSIDA; 2015.

5. Davies M-A. Targeting 909090 don't leave children and adolescents behind. J Int AIDS Soc. 2015;18(Suppl 6):20745 http://www.jiasocietyorg/indexphp/ jias/article/view/20745

6. Baral S, Sifakis F, Cleghorn F, Beyrer C. Elevated risk for HIV infection among men who have sex with men in low- and middle-income countries 20002006: a systematic review. PLoS Med. 2007;4:e339.

7. Liberati A, Altman DG, Tetzlaff J, Mulrow C, Gotzsche PC, loannidis JP, et al, The PRISMA statement for reporting systematic reviews and meta-analyses of studies that evaluate health care interventions: explanation and elaboration. PLoS Med. 2009;6(7):e1000100.

8. Pluye P, Gagnon M-P, Griffiths F. Mixed methods appraisal tool (MMAT). Montréal: Department of Family Medicine, McGill University; 2011.

9. Ekouevi DK, Dagnra CY, Goilibe KB, Tchounga B, Orne-Gliemann J, Salou M, et al. HIV seroprevalence and associated factors among men who have sex with men in Togo. Rev Epidemiol Sante Publique. 2014;62:127-34.

10. Ministère de la Planification, du Développement et de l'Aménagement du Territoire - MPDAT/Togo, Ministère de la Santé - MS/Togo and ICF International. Enquête Démographique et de Santé au Togo 2013-2014. Rockville: MPDAT, MS and ICF International; 2015.

11. Sanders EJ, Graham SM, Okuku HS, van der Elst EM, Muhaari A, Davies A, et al. HIV-1 infection in high risk men who have sex with men in Mombasa. Kenya AIDS. 2007;21:2513-20.

12. Kenya National Bureau of Statistics, Ministry of Health/Kenya, National AIDS Control Council/Kenya, Kenya Medical Research Institute, National Council for Population and Development/Kenya, and ICF International. Kenya Demographic and Health Survey 2014. Rockville: Kenya National Bureau of Statistics, Ministry of Health/Kenya, National AIDS Control Council/Kenya, Kenya Medical Research Institute, National Council for Population and Development/Kenya, and ICF International; 2015

13. Wade AS, Kane CT, Diallo PA, Diop AK, Gueye K, Mboup S, et al. HIV infection and sexually transmitted infections among men who have sex with men in Senegal. AIDS. 2005;19:2133-40.

14. Ndiaye S, Mohamed A. Enquête Démographique et de Santé au Sénégal 2005. Calverton, Maryland, USA: Centre de Recherche pour le Développement Humain/Sénégal and ORC Macro; 2006.

15. Girault P, Green K, Clement NF, Rahman YA, Adams B, Wambugu S. Piloting a social networks strategy to increase HIV testing and counseling among men who have sex with men in Greater Accra and Ashanti region, Ghana. AIDS Behav. 2015;19(11):1990-2000.

16. Ghana Statistical Service - GSS, Ghana Health Service - GHS, and ICF International. Ghana Demographic and Health Survey 2014. Rockville: GSS, GHS, and ICF International; 2015.

17. Mason K, Ketende S, Peitzmeier S, Ceesay N, Diouf D, Loum J, et al. A crosssectional analysis of population demographics, HIV knowledge and risk behaviours, and prevalence and associations of HIV among men who have sex with men in the Gambia. AIDS Res Hum Retrovir. 2013;29:1547-52.

18. The Gambia Bureau of Statistics - GBOS and ICF International. The Gambia demographic and health survey 2013. Banjul: GBOS and ICF International; 2014.

19. Park JN, Papworth E, Kassegne S, Moukam L, Billong SC, Macauley I, et al, HIV prevalence and factors associated with HIV infection among men who have sex with men in Cameroon. J Int AIDS Soc. 2013;16(Suppl 3):18752.

20. Institut National de la Statistique - INS/Cameroun and ICF. International. Enquête Démographique et de Santé et à Indicateurs Multiples du Cameroun 2011. Calverton, Maryland, USA: INS/Cameroun and ICF International; 2012

21. Hladik W, Barker J, Ssenkusu JM, Opio A, Tappero JW, Hakim A, et al. HIV infection among men who have sex with men in Kampala, Uganda--a respondent driven sampling survey. PLoS One. 2012;7:e38143.

22. Ministry of Health/Uganda and ICF International. Uganda AIDS Indicator survey (UAIS) 2011. Calverton Maryland, USA: Ministry of Health/Uganda and ICF International; 2012

23. Wirtz AL, Jumbe V, Trapence G, Kamba D, Umar E, Ketende S, et al. HIV among men who have sex with men in Malawi: elucidating HIV prevalence and correlates of infection to inform HIV prevention. J Int AIDS Soc. 2013; 16(Suppl 3):18742.
24. National Statistical Office - NSO/Malawi and ICF Macro. Malawi Demographic and Health Survey 2010. Zomba: NSO/Malawi and ICF Macro; 2011.

25. Lahuerta M, Patnaik P, Ballo T, Telly N, Knox J, Traore B, et al. HIV prevalence and related risk factors in men who have sex with men in Bamako, Mali: findings from a bio-behavioral survey using respondent-driven sampling. AIDS Behav. 2018;22:2079-88.

26. Cellule de Planification et de Statistique - CPS/SSDSPF/Mali, Institut National de la Statistique - INSTAT/Mali, Centre d'Études et d'Information Statistiques - INFO-STAT/Mali and ICF International. Enquête Démographique et de Santé au Mali 2012-2013. Rockville: CPS, INSTAT, INFO-STAT and ICF International; 2014.

27. Dahoma M, Johnston LG, Holman A, Miller LA, Mussa M, Othman A, et al. HIV and related risk behavior among men who have sex with men in Zanzibar, Tanzania: results of a behavioral surveillance survey. AIDS Behav. 2011;15:186-92.

28. TACAIDS/Tanzania, ZAC/Tanzania, NBS/Tanzania, OCGS/Tanzania, and Macro International. Tanzania HIV/AIDS and Malaria Indicator Survey 2007-08. Dar es Salaam: TACAIDS/Tanzania, ZAC/Tanzania, NBS/Tanzania, OCGS/Tanzania, and Macro International; 2008

29. Kendall C, Kerr LR, Mota RM, Cavalcante S, Macena RH, Chen S, et al. Population size, HIV, and behaviour among MSM in Luanda, Angola: challenges and findings in the first ever HIV and syphilis biological and behavioural survey. J Acquir Immune Defic Syndr. 2014;66(5):544-51.

30. Ministério da Saúde - MINSA/Angola, Ministério do Planeamento e do Desenvolvimento Territorial (MINPLAN) and ICF. Inquérito de Indicadores Múltiplos e de Saúde em Angola 2015-2016. Luanda, Rockville: INE, MINSA, MINPLAN and ICF; 2017.

31. Baral SD, Ketende S, Mnisi Z, Mabuza X, Grosso A, Sithole B, et al. A crosssectional assessment of the burden of HIV and associated individual- and structural-level characteristics among men who have sex with men in Swaziland. J Int AIDS Soc. 2013;16(Suppl 3):18768.

32. Central Statistical Office/Swaziland and Macro International. Swaziland demographic and health survey 2006-07. Mbabane: Central Statistical Office/Swaziland and Macro International; 2008.

33. Baral S, Trapence G, Motimedi F, Umar E, lipinge S, Dausab F, et al. HIV prevalence, risks for HIV infection, and human rights among men who have sex with men (MSM) in Malawi, Namibia, and Botswana. PLoS One. 2009;4:e4997.

34. Ministry of Health and Social Services - MoHSS/Namibia and Macro International. Namibia demographic and health survey 2006-07. Windhoek: MoHSS/Namibia and Macro International; 2008.

35. Lesetedi LT, Mompati GD, Khulumani P, Lesetedi GN, Rutenberg N. Botswana family health survey II 1988. Columbia, Maryland: Central Statistics Office/Botswana, Family Health Division of the Ministry of Health/Botswana, and Institute for Resource Development/Macro Systems; 1989.

36. Elias Dah TT, Koala TS. Social behavioural characteristics, and seroprevalence of HIV infection among men who have sex with men (MSM): about 92 cases collected in a community medical center' Centre OASIS of association african solidarité (AAS) Ouagadougou, Burkina Faso. Sex Transm Infect. 2011;87:A249

37. Institut National de la Statistique et de la Démographie - INSD/Burkina Faso and ICF International. Enquête Démographique et de Santé et à Indicateurs Multiples du Burkina Faso 2010. Calverton, Maryland, USA: INSD and ICF International; 2012.

38. Baral S, Adams D, Lebona J, Kaibe B, Letsie P, Tshehlo R, et al. A crosssectional assessment of population demographics, HIV risks and human rights contexts among men who have sex with men in Lesotho. J Int AIDS Soc. 2011;14:36.

39. Lesotho, Demographic and Health Survey 2014 Ministry of Health/Lesotho and ICF International. Lesotho Demographic and Health Survey 2014. Maseru: Ministry of Health/Lesotho and ICF International; 2016.

40. Hessou S, David-Gnanhoui B, Zeking P, Capo-Chichi V, Sodoloufo O, Ougoudele S. Rapport d'enquête nationale de surveillance de seconde génération (ESDG) des IST/NIH/Sida auprès des hommes ayant des rapports sexuels avec d'autres hommes $(\mathrm{HSH})$ en matière de l'infection à $\mathrm{VIH}$. Cotonou: Plan International Bénin; 2013.

41. Institut National de la Statistique et de l'Analyse Économique - INSAE/Bénin and ICF International. Enquête Démographique et de Santé du Bénin $2011-$ 2012. Calverton, Maryland, USA: INSAE and ICF International; 2013.

42. Boily MC, Shubber Z. Modelling in concentrated epidemics: informing epidemic trajectories and assessing prevention approaches. Curr Opin HIV AIDS. 2014;9(2):134-49. 
43. Programme commun des Nations Unies sur le VIH/sida (ONUSIDA). Global report: UNAIDS report on the global AIDS epidemic 2012. Genève: UNAIDS/WHO; 2012.

44. Wirtz AL, Trapence G, Kamba D, Gama V, Chalera R, Jumbe V, et al. Geographical disparities in HIV prevalence and care among men who have sex with men in Malawi: results from a multisite cross-sectional survey. Lancet HIV. 2017;4(6):e260-e9.

45. Institut National de la Statistique et de l'Analyse Économique - INSAE/Bénin and ICF International. Enquête Démographique et de Santé du Bénin 20112012. Calverton, Maryland, USA: INSAE and ICF International; 2013.

46. Holland CE, Kouanda S, Lougue M, Pitche VP, Schwartz S, Anato S, et al. Using population-size estimation and cross-sectional survey methods to evaluate HIV service coverage among key populations in Burkina Faso and Togo. Public Health Rep. 2016;131(6):773-82.

47. Semaan $\mathrm{S}$. Echantillonnage déterminé selon les répondants pour les populations difficiles à joindre. Methodological Innov Online. 2010;5(2):60-75.

48. Stahlman S, Johnston LG, Yah C, Ketende S, Maziya S, Trapence G, et al. Respondent-driven sampling as a recruitment method for men who have sex with men in southern sub-Saharan Africa: a cross-sectional analysis by wave. Sex Transm Infect. 2016;92(4):292-8.

49. Abdul-Quader AS, Heckathorn DD, McKnight C, Bramson H, Nemeth C, Sabin $\mathrm{K}$, et al. Effectiveness of respondent-driven sampling for recruiting drug users in New York City: findings from a pilot study. J Urban Health. 2006;83(3):459-76.

50. Abdul-Quader AS, Heckathorn DD, Sabin K, Saidel T. Implementation and analysis of respondent driven sampling: lessons learned from the field. J Urban Health. 2006;83(6 Suppl):i1-5.

51. Jarlais D, Duong HT, Pham Minh K, Khuat OH, Nham TT, Arasteh K, et al. Integrated respondent-driven sampling and peer support for persons who inject drugs in Haiphong, Vietnam: a case study with implications for interventions. AIDS Care. 2016;28(10):1312-5.

52. Heckathorn DD. Snowball versus respondent-driven sampling. Sociol Methodol. 2011;41(1):355-66

53. Salganik MJ. Variance estimation, design effects, and sample size calculations for respondent-driven sampling. J Urban Health. 2006;83(6 Suppl):i98-112.

54. Programme commun des Nations Unies sur le VIH/sida (ONUSIDA). Accélérer la riposte: mettre fin à l'épidémie de sida d'ici à 2030. Genève: ONUSIDA; 2016

55. Bemelmans M. Sustaining the future of HIV counselling to reach 90-90-90: a regional country analysis. J Int AIDS Soc. 2016;19:20751.

56. Beyrer C, Sullivan P, Sanchez J, Baral SD, Collins C, Wirtz AL, et al. The increase in global HIV epidemics in MSM. AIDS. 2013;27(17):2665-78.

57. Lloyd J, Papworth E, Grant L, Beyrer C, Baral S. Systematic review and metaanalysis of HIV prevalence among men in militaries in low income and middle income countries. Sex Transm Infect. 2014;90(5):382-7.

\section{Publisher's Note}

Springer Nature remains neutral with regard to jurisdictional claims in published maps and institutional affiliations.

\section{Ready to submit your research? Choose BMC and benefit from:}

- fast, convenient online submission

- thorough peer review by experienced researchers in your field

- rapid publication on acceptance

- support for research data, including large and complex data types

- gold Open Access which fosters wider collaboration and increased citations

- maximum visibility for your research: over $100 \mathrm{M}$ website views per year

At $\mathrm{BMC}$, research is always in progress.

Learn more biomedcentral.com/submissions 